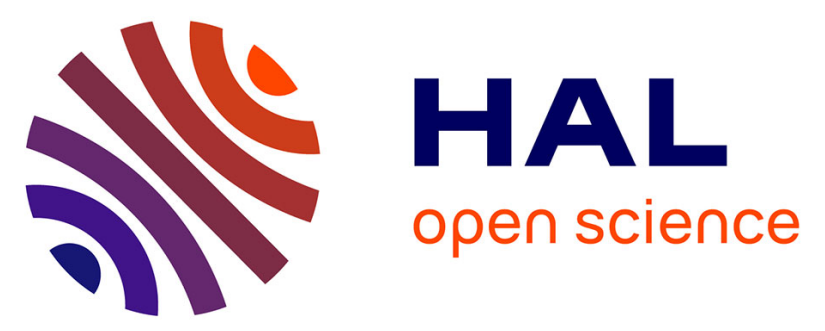

\title{
Model development of sustainability assessment from a life cycle perspective: A case study on waste management systems in China
}

\author{
Zhaozhi Zhou, Yong Chi, Jun Dong, Yuanjun Tang, Mingjiang Ni
}

\section{- To cite this version:}

Zhaozhi Zhou, Yong Chi, Jun Dong, Yuanjun Tang, Mingjiang Ni. Model development of sustainability assessment from a life cycle perspective: A case study on waste management systems in China: Review. Journal of Cleaner Production, 2019, 210, pp.1005-1014. 10.1016/j.jclepro.2018.11.074 . hal-01944081

\section{HAL Id: hal-01944081 https://imt-mines-albi.hal.science/hal-01944081}

Submitted on 17 Jan 2019

HAL is a multi-disciplinary open access archive for the deposit and dissemination of scientific research documents, whether they are published or not. The documents may come from teaching and research institutions in France or abroad, or from public or private research centers.
L'archive ouverte pluridisciplinaire HAL, est destinée au dépôt et à la diffusion de documents scientifiques de niveau recherche, publiés ou non, émanant des établissements d'enseignement et de recherche français ou étrangers, des laboratoires publics ou privés. 


\title{
Model development of sustainability assessment from a life cycle perspective: A case study on waste management systems in China
}

\author{
Zhaozhi Zhou ${ }^{\text {a, }}$ Yong Chi ${ }^{\text {a, }}{ }^{*}$, Jun Dong ${ }^{b}$, Yuanjun Tang a, Mingjiang $\mathrm{Ni}^{\text {a }}$ \\ a State Key Laboratory of Clean Energy Utilization, Zhejiang University, Hangzhou, China \\ ${ }^{\mathrm{b}}$ Centre RAPSODEE, Ecole des Mines Albi, Campus Jarlard, 81013, Albi Cedex, France
}

\begin{abstract}
A B S T R A C T
Due to the problems of municipal solid waste (MSW) during the expanding urbanization, strategy to find an environmentally friendly, energy efficient, cost-effective, and socially acceptable MSW management system is essential for sustainable development. This study establishes a novel environment-energyeconomy-society $(3 \mathrm{E}+\mathrm{S})$ model from a life cycle perspective for sustainability assessment: life cycle assessment for evaluating environmental performance and energy consumption, life cycle costing for recording economic burden, and social life cycle assessment for reflecting social impacts; based on the individual $3 \mathrm{E}+\mathrm{S}$ results, the final ranking of alternatives is obtained by multi-criteria decision making, which is integrated with analytic hierarchy process and entropy weight method. This model is implemented to identify a sustainable MSW management system among four typical treatment alternatives. Results show that incineration with fluidized bed furnace is the best choice in this study; incineration with moving grate furnace follows after with a slight gap; landfill with and without energy recovery rank the third and the last. The framework of SLCA on MSW field is built in this study and sensitivity analysis is provided for further discussion on social impacts. The calculation method of weight factors reduces man-made disturbances and the sensitivity analysis demonstrates strong robustness of the results and effectiveness of the modification for the model.
\end{abstract}

\section{Introduction}

Driven by the rapid economic development and urban population growth, China has witnessed fast-paced urban development. However, urbanization also brings a variety of environmental issues, which pose a threat to sustainable development. One of the problems is generation of municipal solid waste (MSW). In 2016, the annual MSW generation in China reached 203.6 Mt; landfill and incineration are main treatment methods, accounting for $60.3 \%$ and 37.5\% of the total collected MSW (Chinese Statistics Yearbook Compiling Committee, 2017). Because of the advantages of MSW incineration in waste reduction and energy recovery, more incineration plants are under construction. Toxic emissions, such as dioxin and heavy metals, are released from MSW incineration plants and become the threat to ecosystem and human health (Othman et al., 2013). An appropriate assessment method is needed for sustainable MSW management system.

\footnotetext{
* Corresponding author.

E-mail address: chiyong@zju.edu.cn (Y. Chi).
}

Life cycle assessment (LCA) is a successful tool to consider all inputs and outputs of materials and energy throughout the life cycle and identify the environmental impacts and energy consumption (ISO et al., 2006). LCA has been widely adopted for waste treatment technologies. Evangelisti et al. (2015) conducted LCA to compare the advanced waste-to-energy (WtE) technologies with conventional treatments. Astrup et al. (2015) reviewed 250 LCA studies on WtE published between 1995 and 2013. Nonetheless, only taking into account energy and environmental performances cannot comprehensively reflect the functioning of an MSW management system. Based on its basic framework, several novel methods have been developed to extend LCA for special purpose, e.g. integrated with engineering design tool for eco-design (Tao et al., 2018), combined with exergy analysis for calculating resource efficiency (Risse et al., 2017), or complemented with economic assessment (Galli et al., 2018). Zhou et al. (2018) summarized a concrete overview of LCA extension methods on WtE. An energy-environment-economy (3E) assessment model was established in the previous work (Dong et al., 2014b). The 3E model consists of LCA and life cycle costing (LCC), accounting for energy, 
environment and cost, and solves the inconsistencies between LCA and LCC. The model was applied successfully to evaluate different MSW treatment systems (Dong et al., 2014b). Social resistance, e.g. mass protests, is also a hindrance for licensing, construction and operation of MSW treatment facilities, which cannot be reflected by a $3 \mathrm{E}$ model.

The 6th and 7th EU Framework Programme proposed the development of sustainability assessment, concerning the environmental, economic and social aspects (Zhou et al., 2018), but the explorations on sustainability assessment are still limited. Huang et al. (2012) evaluated the sustainability performance of building sectors, but only considered few environmental impacts. Vinyes et al. (2013) added social life cycle assessment (SLCA) into the study to quantify social burdens, but did not integrate individual results into one final result. Only few SLCA studies on waste treatment have been published, e.g. composting of organic waste (Foolmaun and Ramjeeawon, 2013), recycling system for electronic waste (Umair et al., 2015), flake production by used bottles (Martínez-Blanco et al., 2014), but none on WtE techniques. Several other sustainability assessment methods were also utilized on various fields, but their methods, especially frameworks of SLCA, were not suitable for the MSW (Santoyo-Castelazo and Azapagic, 2014). Sustainability assessment methods on MSW treatment technology are still lacking. A comprehensive assessment model that can reflect environmental, energy, economic, and social impacts simultaneously is necessary for sustainable development of MSW management system (Kloepffer, 2008).

In regard to multi-objection assessment, multi-criteria decision making (MCDM) is a common method to provide solutions to problems involving conflicts and multiple objectives (Yazdani et al., 2017), and reasonable weight factors provided from mathematical approach can extend its scientific base. Analytic hierarchy process (AHP) is widely implemented to determine the associated weight factors (Yagmur, 2016); decision-maker experience and preferences are the basis for its judgment but cause the possible subjectivity (Dong et al., 2014b). Entropy weight method is another method based on the inherent information entropy of raw data, but it cannot reflect the priority judged by stakeholder groups (Liu and Zhang, 2011). The linear programming is also used to analyze the MSW management but this model is limited to scenarios with simple waste flow routes, and complex combinations make the mathematical model non-linear (Mora, 1996). A scientific method for calculating the weight factors is essential for a sustainability assessment model.

The aim of this study is to extend the previous 3E model towards a $3 \mathrm{E}+\mathrm{S}$ (society) model involving social factors and to optimize the calculation of weight factors. The novel $3 \mathrm{E}+\mathrm{S}$ model considers environmental, energy, economic, and social aspects simultaneously and its indicators are modified to meet the sustainable requirements of the MSW management system. The MSW treatment systems in Hangzhou, China, is analyzed as a case study.

\section{Methods}

\subsection{Definition of sustainability assessment}

A $3 \mathrm{E}+\mathrm{S}$ model is established for sustainability assessment from a life cycle perspective: environmental impacts and energy consumption are examined by LCA, while economic burden and social impacts are analyzed by LCC and SLCA; results of the four aspects are analyzed by MCDM and the associated weight factors are calculated by the integration of AHP and entropy weight method. The framework is illustrated in Fig. 1 and its features are described as follows.

\subsection{LCA for environmental and energy assessment}

According to ISO 14040, LCA consists of four steps: goal and scope definition, life cycle inventory (LCI), life cycle impact assessment (LCIA) and interpretation (ISO et al., 2006).

The environmental performance can be calculated through four steps: classification, characterization, normalization and weighting. Based on the LCI results, the LCIA method CML 2001 is used for environmental assessment in this study and seven environmental impacts are considered: global warming potential (GWP), acidification potential (AP), eutrophication potential (EP), photochemical ozone creation potential (POCP), freshwater aquatic ecotoxicity potential (FAETP), human toxicity potential (HTP), and terrestric ecotoxicity potential (TETP). The negative value demonstrates a benefit to the corresponding environmental potentials.

The energy consumption mainly considers the stages of fuel consumption, fuel production, auxiliary material production, electricity consumption and recovery, and avoided energy resulted from by-product production. Energy performance is a sum of all the energy consumptions and a negative value means a net energy recovery.

\subsection{LCC for economic assessment}

LCC is an economic method that aggregates all monetary costs of a product or system during the entire life cycle, including investment cost, operating cost, decommissioning cost, and projected revenue.

As a part of $3 \mathrm{E}+\mathrm{S}$ model, $\mathrm{LCC}$ is required to have the same time

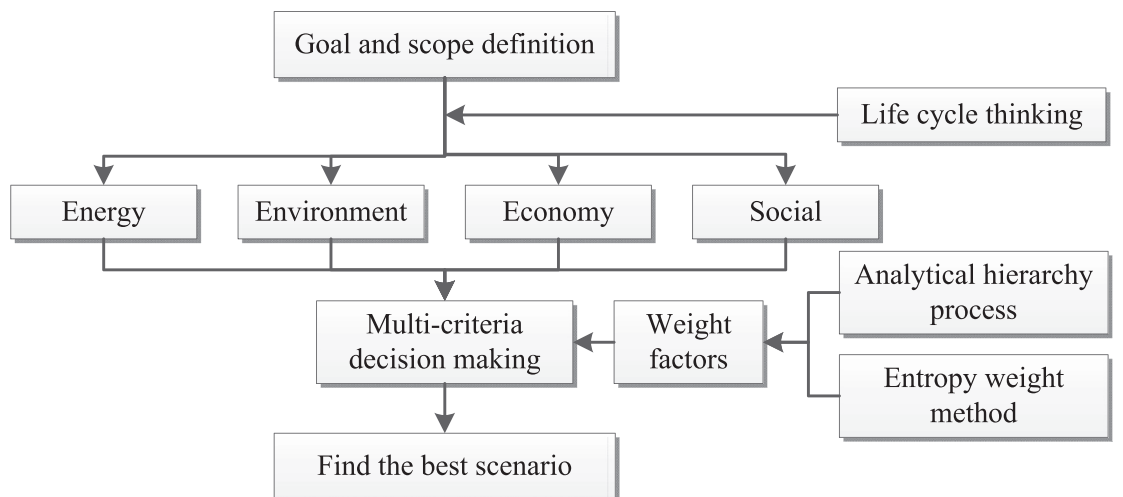

Fig. 1. Framework of the $3 \mathrm{E}+\mathrm{S}$ model. 
boundary and functional unit as LCA. Costs associated with environmental impacts are not considered in this analysis. All the costs are here defined as the present value. Considering the time value of money, a discounting rate is considered and future costs are discounted by Eq. (1) (Gluch and Baumann, 2004):

$P V=F V \times \frac{1}{(1+a)^{t}}$

where, $P V$ is the present value; $F V$ is the future value; $a$ is discounting rate; and $t$ is its life time.

\subsection{SLCA for social assessment}

SLCA is a methodological approach for determining the social impacts. Stakeholders are vital factors in SLCA and each has its special subcategories. UNEP-SETAC Guidelines cited five stakeholder categories, 31 subcategories, and more than 100 related indicators (UNEP-SETAC, 2009). Applicable stakeholder categories and social indicators should be selected for the special study (Zhou et al., 2018).

In this study, three stakeholder categories (worker, local community, and society) and eight corresponding subcategories are considered. Each subcategory involves several social indicators. The framework of SLCA for waste treatment system is illustrated in Table A.1SM, available as Supplementary material available online. Social indicators for each scenario are compared and a score is applied to each indicator with a score system from 1 (being the worst) through 3 (being the best). The score within each indicator is then averaged. The scores of indicators under the same subcategory are then averaged and the average score is assigned to the corresponding subcategory. The subcategories are assumed to have equal weighting and all the weight factors are set as 1 . All the subcategory scores are summed to obtain a single score for the social performance.

\section{5. $M C D M$ for $3 E+S$ integration}

AHP weight factors are calculated by using pair-wise comparison. Saaty's method, which uses a scale of $1-9$, is adopted to rate the relative importance of criteria, where higher numbers indicate greater importance (Saaty, 1990). Consistency ratio (CR) is used to check the judgement inconsistencies (Govindan et al., 2014). The mathematical approaches are illustrated in Supplementary material. The priority of each alternative from the point of view of different stakeholders is typically distinct, thus, the weight results may result in a controversy.

Entropy weight method is based on the information entropy of raw data. Entropy reflects the disorder degree of the system. When the difference among the alternatives in the same criterion is high, its information entropy is small, demonstrating that the criterion provides more useful information and its weight factor should be set correspondingly high (Li et al., 2011). The mathematical model formulations are provided in Supplementary material. Weight results obtained by the entropy weight method are determined by information data, eliminating man-made disturbances (Zou et al., 2006). These weights factors do not reflect the importance of the criteria to stakeholder groups, thus, several additional factors are suggested to combine with this method.

AHP and entropy weight method can complement each other and the final weight factors integrate the weight factors by AHP and entropy weight method, as calculated in Eq. (2): $u_{j}=\frac{\left(w_{j} \times h_{j}\right)^{0.5}}{\sum_{j=1}^{n}\left(w_{j} \times h_{j}\right)^{0.5}}$

where, $u_{j}$ is a final weight factor for each criterion; $w_{j}$ is a weight factor for each criterion by AHP; $h_{j}$ is the weight factor for each criterion by entropy weight method.

TOPSIS (which stands for Technique for Order Preference by Similarity to an Ideal Solution) is utilized to rank the alternatives and propose a solution to decision-maker (Opricovic and Tzeng, 2004). The ideal solution, which is defined as the best alternative for each criterion, is given a score of 1 and the worst a score of 0 . Other alternatives are then ranked based on their geometric distance from the ideal solution and negative solution (Chen and Hwang, 1992). The calculation formulations are presented in Supplementary material. Weights, as determined via the methods above, are then applied to each criterion and a final ranking of alternatives is determined for the decision-maker.

\section{Case study-application of $3 E+S$ model}

\subsection{Goal and scope definition}

This study aims to adopt the $3 \mathrm{E}+\mathrm{S}$ model to evaluate the sustainability performance of MSW treatment systems in China. Hangzhou, a city with an advanced economy and dense population in China, is selected as the case city. Hangzhou generated $3,684,946$ t-MSW in 2016, with a ten-year growth rate of $116.3 \%$ (Hangzhou Statistics Yearbook Compiling Committee, 2017). Its MSW management system involved one landfill plant and five incineration plants, all of which were equipped with WtE devices. Among them, three incineration plants utilized FB technologies and two utilized MG technologies. Because landfill without energy recovery is common in China, this scenario is also considered in the study. Four types of MSW treatment systems are evaluated and compared: 1) landfill without energy recovery, landfill gas is not collected; 2) landfill with energy recovery, landfill gas is used for electricity production; 3 ) incinerate using FB technology and produce electricity and 4) incinerate using MG technology and produce electricity. The four scenarios along with system boundaries are shown in Fig. 2. Process of waste treatment, electricity production, leachate treatment and ash disposal are all involved. MSW collection process and transportation from collection point to treatment plant is excluded because it is considered the same for all the scenarios. Labor is considered in LCC and SLCA, but ignored in LCA, and plant construction and decommissioning are only calculated in LCC.

The function unit is defined as one t-MSW and is available for LCA and LCC, i.e. all the input and output of material and energy, including financial costs, are normalized to this basis. Social indicator results for SLCA are scored based on their relative performances and it is difficult to relate the social impacts to the function unit (Zhou et al., 2018).

System expansion with regard to the generated electricity and by-product, is adopted as the allocation method. Electricity generated is sent to the grid and provides the "avoided" emissions, energy-consumption, costs by displacing the equivalent amount of electricity produced from China's mixed power grid. The credits from the by-product (brick) are provided by substituting the brick production in conventional manner.

To evaluate the performances, some assumptions are made:

(1) For environmental impacts, discharges into the soil are not considered in this study due to the unavailable data. 


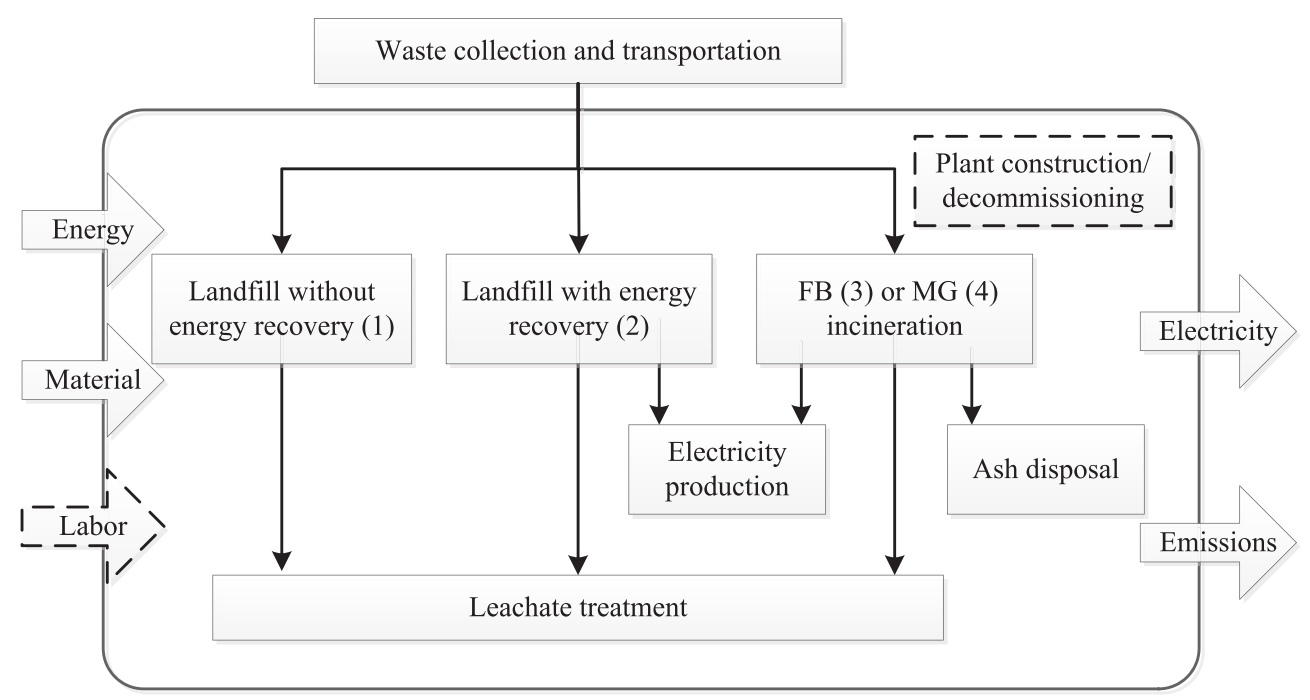

Fig. 2. System boundary of the study. "Labor" is considered in LCC and SLCA, but not in LCA; "Plant construction/decommissioning" is taken into account in LCC.

(2) For economic calculation, the plant demolition cost is assumed to be equal to its residual value and thus the decommissioning cost is neglected. Offset by the costs of auxiliary materials for treating bottom ash, the revenue from generated brick can be ignored. Gate fees paid by the government are not considered in this study.

(3) For social impacts, it is assumed that incineration scenarios 3 and 4 have the same social impact results.

\subsection{Inventory analysis}

The data in this study are mainly obtained from on-site visits of the treatment plants, surveys with plant operators, and reports by Hangzhou municipal solid waste disposal supervision center. Background data related to raw material production are obtained from Gabi 8.0 software database (Thinkstep, 2018).

Scenarios 1 and 2 are the landfill scenarios. The selected landfill site, with an annual capacity of $962,000 \mathrm{t}$, are assumed to be in operation for $23 \mathrm{y}$ as designed. The MSW is typically deposited by sanitary landfill and leachate is directed to the on-site leachate treatment system. The total approximated amount of the released landfill gas is $125.6 \mathrm{~m}^{3}$ per t-MSW. Methane accounts for $54.5 \%$ of the total gas (Dong et al., 2014a). The landfill gas in scenario 1 is emitted to atmosphere directly, whereas in scenario 2, 70\% of landfill gas is collected and directed to a gas engine for electricity production with an efficiency of 39.1\% (Dong et al., 2014a).

Scenarios 3 and 4, FB and MG incinerations, are two typical technologies of MSW incineration. Information about the selected incineration plants are illustrated in Table 1. Both incineration

Table 1

Operation data of two selected incineration plants.

\begin{tabular}{llll}
\hline & Unit & Scenario 3 & Scenario 4 \\
\hline $\begin{array}{l}\text { Furnace } \\
\text { Capacity }\end{array}$ & t/d & FB & MG \\
$\begin{array}{l}\text { Energy recovery } \\
\quad \text { Electricity efficiency }\end{array}$ & \% & 1200 & 3000 \\
$\quad \begin{array}{l}\text { Electricity for own use } \\
\text { Solid residues }\end{array}$ & \% of produced & 25.2 & 22.5 \\
$\quad$ Bottom ash & \% of MSW & 18.1 & 15 \\
$\quad$ Fly ash & \% of MSW & 9.9 & 18.3 \\
\hline
\end{tabular}

plants are assumed to have a 30-year service life. The plants in both scenarios are equipped with advanced air pollution control and leachate treatment systems. Bottom ash is typically formed into bricks, which are sold directly from the plant. Fly ash is solidified and transported to a hazardous landfill (Havukainen et al., 2017). The FB furnace incineration plant utilized coal as auxiliary fuel to maintain stable burning, at a ratio of $50 \mathrm{~kg}$ per t-MSW.

The heating value and fossil carbon content of MSW and auxiliary coal, (provided in Table A.4SM), determine the total generated electricity and carbon dioxide $\left(\mathrm{CO}_{2}\right)$ emissions. The electricity efficiencies are illustrated in Table 1. A small part of the total generated electricity remains at the plant for selfconsumption and the rest is sent to the electric grid. Other types of emissions are obtained from the operation reports. Because the selected MG incineration plant was still in trial operation during investigation, the data of material consumption and emissions are collected from another incineration facility with same capacity and technology.

\subsubsection{Life cycle inventory}

Table 2 gives a list of inputs and outputs of materials and energy in the system boundary, which is a basis for the calculation related to the environmental impacts and energy consumption.

\section{Results and discussion}

\section{1. $3 E+S$ results}

Fig. 3 provides the environmental results of each category and Fig. 4 presents the contributions of each process to the environmental performance. The detailed characterized results are provided in Fig. A.1SM. GWP is the main contributor to final result among the conventional categories. Landfill emits high amounts of methane, which has a GWP 28 times that of $\mathrm{CO}_{2}$, leading to the high GWP. Because of the gas collection system, scenario 2 has a lower value of GWP than scenario 1.4 performs best in GWP, because coal is taken as auxiliary fuel and produce a high amount of $\mathrm{CO}_{2}$ in scenario 3.HTP is the main contributor in toxicity categories, while other categories do not affect the final result significantly. Incineration produces dust, heavy metals, and dioxins, and these are main factors in toxicity categories. Although higher environmental burdens from direct emissions are obtained to scenario 3 and 4 , 
Table 2

Inventory of each scenario for the treatment of $1 \mathrm{t}-\mathrm{MSW}$.

\begin{tabular}{|c|c|c|c|c|c|}
\hline & Unit & Scenario 1 & Scenario 2 & Scenario 3 & Scenario 4 \\
\hline \multicolumn{6}{|l|}{ Input } \\
\hline Electricity & kWh & 0.42 & 1.56 & 74.27 & 45.50 \\
\hline Diesel for mechanical operation & $\mathrm{kg}$ & 0.14 & 1.07 & 1.96 & 2.18 \\
\hline Diesel for transportation & $\mathrm{kg}$ & 0.00 & 0.00 & 0.25 & 0.10 \\
\hline High density polyethylene & $\mathrm{kg}$ & 0.33 & 0.45 & 0.00 & 0.00 \\
\hline Clay & $\mathrm{kg}$ & 59.70 & 59.70 & 0.00 & 0.00 \\
\hline Sodium chloride & $\mathrm{kg}$ & 0.37 & 0.37 & 0.00 & 0.00 \\
\hline Limestone & $\mathrm{kg}$ & 0.77 & 0.77 & 0.00 & 0.00 \\
\hline Calcium hydroxide & $\mathrm{kg}$ & 0 & 0 & 18.14 & 13.50 \\
\hline Ammonia water (25\%) & $\mathrm{kg}$ & 0 & 0 & 8.94 & 3.60 \\
\hline Coal & $\mathrm{kg}$ & 0 & 0 & 50 & 0 \\
\hline Lubricating oil & $\mathrm{kg}$ & 0 & 0 & 0.04 & 0.04 \\
\hline Cement & $\mathrm{kg}$ & 0 & 0 & 39.27 & 56.10 \\
\hline \multicolumn{6}{|l|}{ Output } \\
\hline Electricity & kWh & 0 & 157.31 & 412.61 & 303.36 \\
\hline Brick & $\mathrm{kg}$ & 0 & 0 & 157.30 & 237.90 \\
\hline Fly ash & $\mathrm{kg}$ & 0 & 0 & 99 & 40 \\
\hline Leachate & $\mathrm{kg}$ & 200 & 200 & 60 & 60 \\
\hline \multicolumn{6}{|l|}{ Emissions to air } \\
\hline Carbon dioxide, fossil & $\mathrm{kg}$ & 0 & 0 & 511.77 & 430.19 \\
\hline Carbon monoxide & $\mathrm{kg}$ & 0 & 0.07 & 0.20 & 0.19 \\
\hline Methane & $\mathrm{kg}$ & 73.64 & 22.09 & 0 & 0 \\
\hline Hydrogen chloride & $\mathrm{kg}$ & 0 & 0.04 & 0.02 & 0.21 \\
\hline Hydrogen fluoride & $\mathrm{kg}$ & 0 & 0 & 8.91E-03 & $8.91 \mathrm{E}-03$ \\
\hline Nitrogen oxides & $\mathrm{kg}$ & 0 & 0.06 & 0.48 & 0.85 \\
\hline Sulfur dioxide & $\mathrm{kg}$ & 0 & 0.03 & 0.09 & 0.29 \\
\hline Nitrous oxide & $\mathrm{kg}$ & 0 & 0 & 0.05 & 0.05 \\
\hline Ammonia & $\mathrm{kg}$ & 0.19 & 0.08 & $5.95 \mathrm{E}-03$ & $5.95 \mathrm{E}-03$ \\
\hline Hydrogen sulfide & $\mathrm{kg}$ & 0.38 & 0.17 & 2.77E-04 & 2.77E-04 \\
\hline $\mathrm{VOCs}^{\mathrm{a}}$ & $\mathrm{kg}$ & 0.12 & 0.05 & 0 & 0 \\
\hline $\mathrm{PM}_{10}{ }^{\mathrm{a}}$ & $\mathrm{kg}$ & 7.74E-05 & 7.74E-05 & 0.09 & 0.03 \\
\hline PCDD/DFs ${ }^{\mathrm{a}}$ & $\mathrm{kg}$ & 0 & $2.40 \mathrm{E}-10$ & $6.29 \mathrm{E}-10$ & $3.01 \mathrm{E}-10$ \\
\hline Mercury & $\mathrm{kg}$ & 8.36E-08 & $3.41 \mathrm{E}-08$ & $2.16 \mathrm{E}-05$ & $1.46 \mathrm{E}-04$ \\
\hline Lead & $\mathrm{kg}$ & 0 & 0 & $9.62 \mathrm{E}-06$ & $4.38 \mathrm{E}-04$ \\
\hline Cadmium & $\mathrm{kg}$ & 0 & 0 & $9.62 \mathrm{E}-06$ & $3.65 \mathrm{E}-05$ \\
\hline \multicolumn{6}{|l|}{ Emissions to water } \\
\hline $\mathrm{NH}_{3}-\mathrm{N}^{\mathrm{a}}$ & $\mathrm{kg}$ & 0.20 & 0.20 & 3.27E-04 & 3.27E-04 \\
\hline $\mathrm{T}-\mathrm{P}^{\mathrm{a}}$ & $\mathrm{kg}$ & $2.38 \mathrm{E}-03$ & $2.38 \mathrm{E}-03$ & $1.62 \mathrm{E}-05$ & $1.62 \mathrm{E}-05$ \\
\hline $\mathrm{BOD}^{\mathrm{a}}$ & $\mathrm{kg}$ & 0.08 & 0.08 & $9.00 \mathrm{E}-04$ & $9.00 \mathrm{E}-04$ \\
\hline $\mathrm{COD}^{\mathrm{a}}$ & $\mathrm{kg}$ & 0.23 & 0.23 & $3.00 \mathrm{E}-03$ & $3.00 \mathrm{E}-03$ \\
\hline Cadmium & $\mathrm{kg}$ & $6.00 \mathrm{E}-06$ & $6.00 \mathrm{E}-06$ & $3.00 \mathrm{E}-06$ & 3.00E-06 \\
\hline Copper & $\mathrm{kg}$ & 4.90E-05 & $4.90 \mathrm{E}-05$ & $1.74 \mathrm{E}-05$ & $1.74 \mathrm{E}-05$ \\
\hline Chromium & $\mathrm{kg}$ & $2.00 \mathrm{E}-05$ & $2.00 \mathrm{E}-05$ & $2.94 \mathrm{E}-06$ & $2.94 \mathrm{E}-06$ \\
\hline Lead & $\mathrm{kg}$ & $1.00 \mathrm{E}-04$ & $1.00 \mathrm{E}-04$ & $8.40 \mathrm{E}-06$ & $8.40 \mathrm{E}-06$ \\
\hline Zinc & $\mathrm{kg}$ & $4.50 \mathrm{E}-05$ & $4.50 \mathrm{E}-05$ & $6.42 \mathrm{E}-06$ & $6.42 \mathrm{E}-06$ \\
\hline Nickel & $\mathrm{kg}$ & $1.15 \mathrm{E}-04$ & $1.15 \mathrm{E}-04$ & $2.38 \mathrm{E}-05$ & $2.38 \mathrm{E}-05$ \\
\hline Mercury & $\mathrm{kg}$ & $7.22 \mathrm{E}-06$ & $7.22 \mathrm{E}-06$ & $1.14 \mathrm{E}-07$ & $1.14 \mathrm{E}-07$ \\
\hline
\end{tabular}

${ }^{a}$ VOCs: volatile organic compounds; $\mathrm{PM}_{10}$ : particulate matter of diameter $\leq 10 \mu \mathrm{m}$; PCDDs: polychlorinated dibenzo-p-dioxins; PCDFs: polychlorinated dibenzop-dioxins; $\mathrm{NH}_{3}-\mathrm{N}$ : ammonia nitrogen; T-P: total phosphorus; BOD: biochemical oxygen demand; COD: chemical oxygen demand.

they still have better performances in HTP than other scenarios.

As seen in Fig. 4, emissions from treatment process are the main burdens to the environmental performances for all the scenarios, while electricity generation contributes the most to environmental preservation. The burdens from raw material production in scenarios 3 and 4 are much higher than in scenarios 1 and 2 . Because of the avoided emissions from by electricity and by-product production, scenarios 3 and 4 demonstrate the most environmentally favorable performances. Consequently, scenario 3 has the best environmental favorability; scenarios 4 and 2 rank the second and third best; scenario 1 is the only scenario with positive value and damage to environment.

In regard to energy, results shown in Fig. 5 indicate that scenario 1 obtains the highest value and the other scenarios have negative net energy consumption. Auxiliary materials production is the main contributor in scenarios 1,2 and 4 and constituted of $97 \%, 87 \%$ and $69 \%$ in total energy use. Since coal is taken as an auxiliary fuel and combusted together with MSW, scenario 3 has highest fuel consumption and production. Electricity and brick production are special stages, which can avoid primary energy consumption. Because of high energy recovery in scenarios 2, 3 and 4, the initial energy consumed can be compensated and these scenarios achieve energy recovery. Overall, scenario 4 demonstrates the best scenario in energy; because of the highest energy recovery but highest energy consumption, scenario 3 ranks the second and is better than scenario 2; scenario 1 shows the worst outcome mainly due to the lack of energy recovery.

The economic results of each scenario are shown in Table 3 and negative values indicate revenues. The discounted rate is set as 5\% based on the financial feasibility (Dong et al., 2014b). Scenario 1 has the lowest investment and operation cost due to the absence of power generating equipment. Scenarios 3 and 4 have the greatest investment costs due to the high cost of building and equipment for the incinerators. Operation costs show the greatest variation between scenarios. Incineration scenarios show much higher operation costs than landfill scenarios mostly due to the more complex mechanical equipment and disposal of fly ash. Scenario 3Exhibits slightly higher operation cost than scenario 4 mainly because of the 


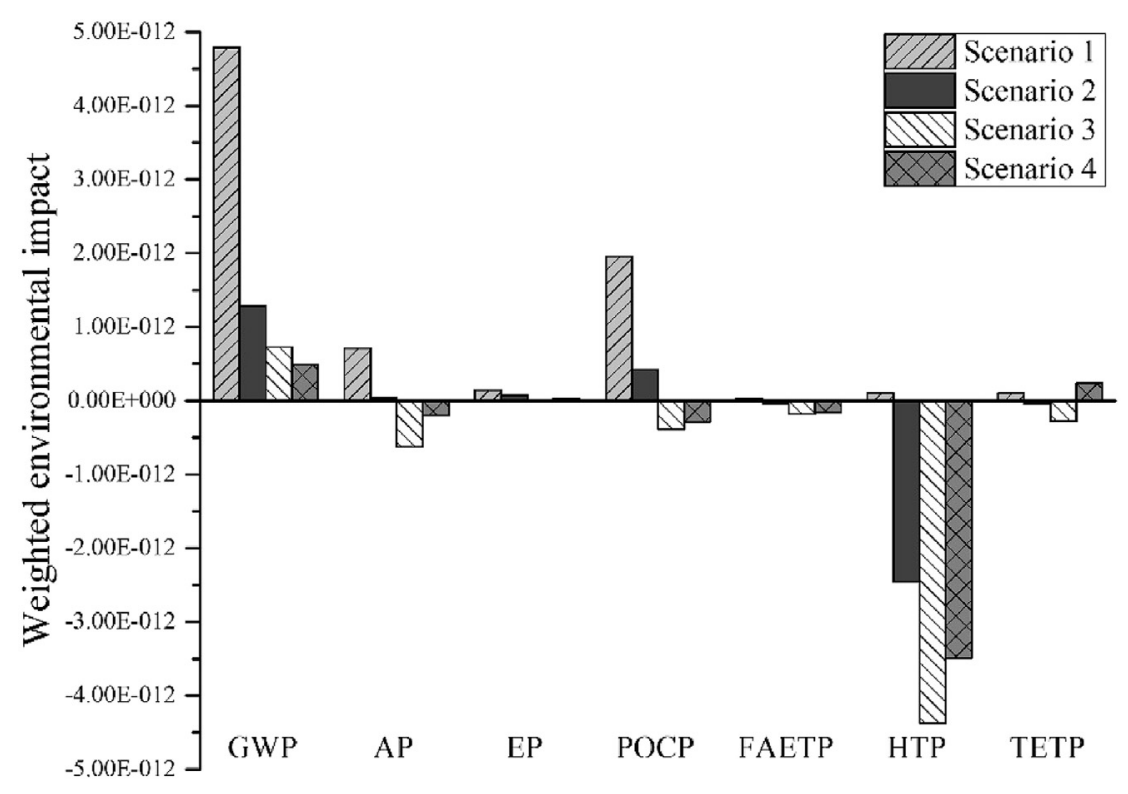

Fig. 3. Environmental impacts of each category.

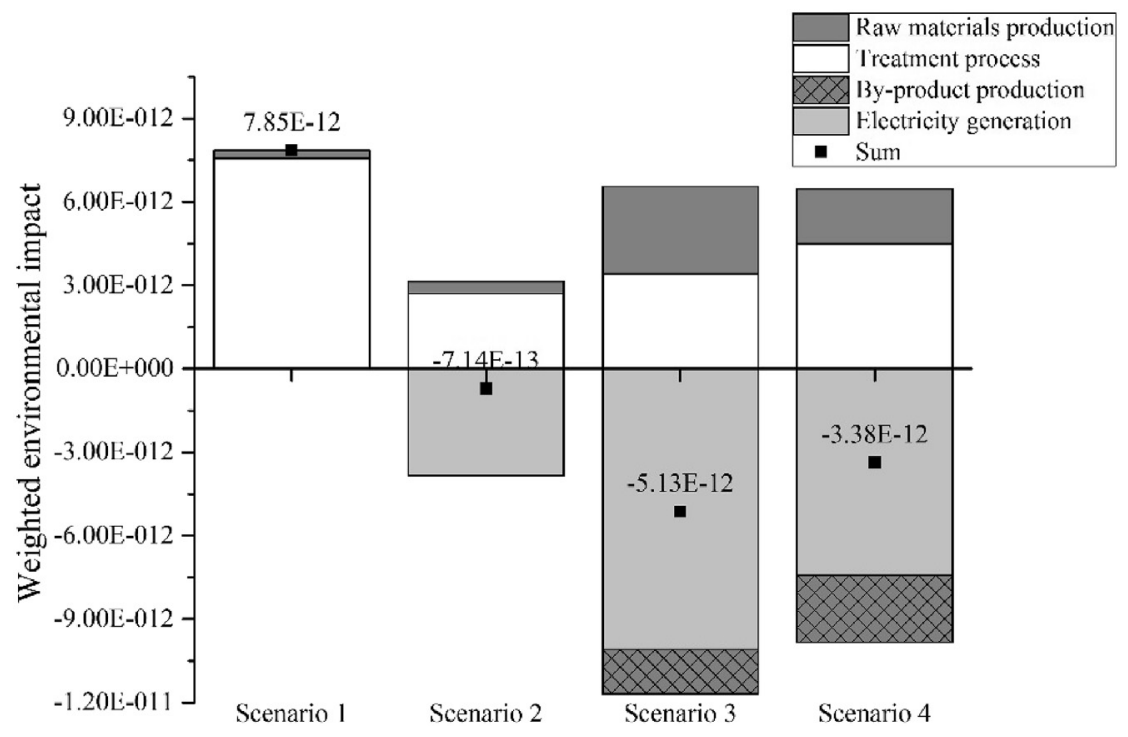

Fig. 4. Environmental results of each scenario.

high amount of fly ash and consumption of the auxiliary coal. Credit from electricity production is the only positive financial inflow offsetting the overall cost. Although more revenue is obtained in incineration scenarios, their total costs are still higher than for the landfill scenarios. From economic perspective, scenario 2 shows the best performance with scenarios 1 and 3 ranking behind it; scenario 4 is the most expensive choice.

Table 4 compares the social subcategory results for the scenarios. The detailed scores of social indicators are illustrated in Table A.5SM. Without child labor and forced labor, all scenarios have good performances in working condition. Because of the least potential risk of the working process, scenario 1 shows the highest scores in workers' health and safety. Regarding the stakeholder of society, scenario 1 has the worst performance and other scenarios have the same score.

Local community is the main stakeholder category for the waste treatment systems. Because less land is occupied, incineration scenarios typically have better performance than landfill scenarios in access to material resources. Emissions of all the scenarios can meet the national standards, however, the noise associated with the incineration sometimes exceeds the standard, slightly worsening the performance in safe and healthy living condition. Incineration scenarios need more workers, thus, they promote local employment. Regarding secure living conditions, security conflicts and protests associated with construction and operation of incineration plants are impacting negatively incineration scenarios; landfill scenarios also cannot solve the same dilemma very well. Therefore, scenarios 3 and 4 demonstrate the best social performance with scenario 2 ranking after and scenario 1 being the worst.

The weight factors are calculated by the integration of AHP and entropy weight method. Regarding AHP, priority of the criteria is ranked based on the governmental policies and the greatest 


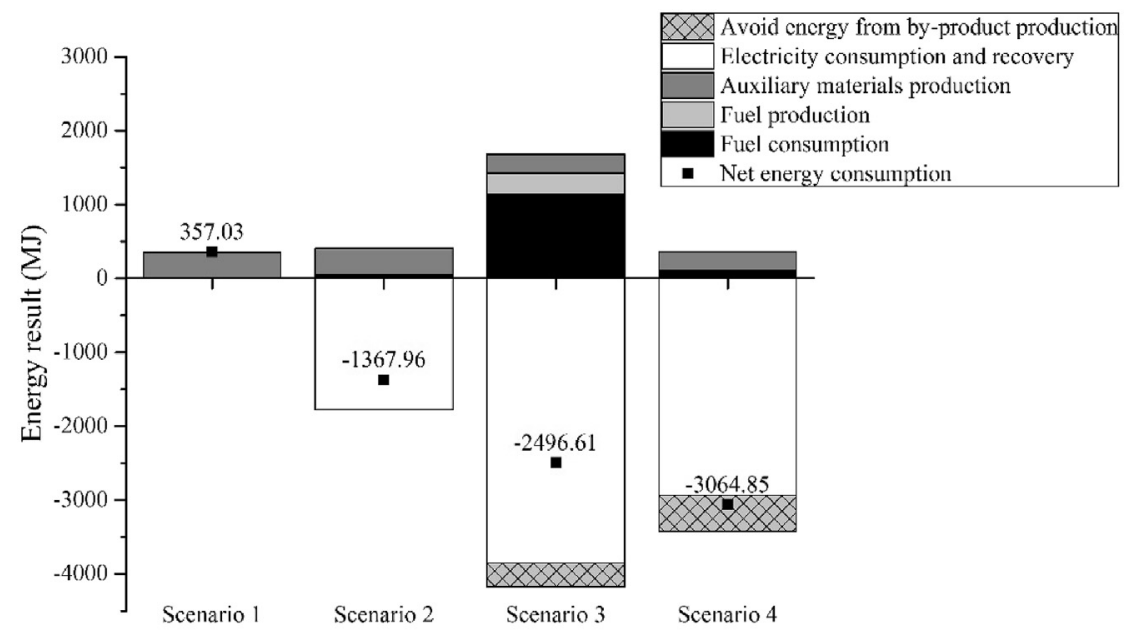

Fig. 5. Energy results of each scenario.

Table 3

Economic results of each scenario (unit: CNY per t-MSW).

\begin{tabular}{|c|c|c|c|c|}
\hline & \multicolumn{4}{|c|}{ Scenario } \\
\hline & 1 & 2 & 3 & 4 \\
\hline Project timeframe (year) & 25 & 25 & 30 & 30 \\
\hline Investment cost & 18.83 & 21.78 & 34.64 & 56.60 \\
\hline Operation cost & 27.04 & 52.99 & 135.19 & 99.91 \\
\hline Revenue & 0 & -58.20 & -112.69 & -85.88 \\
\hline Net economic result & 45.87 & 16.57 & 57.14 & 70.62 \\
\hline
\end{tabular}

Table 4

Social impacts of each scenario.

\begin{tabular}{lllll}
\hline Subcategory & \multicolumn{3}{l}{ Scenario } \\
\cline { 2 - 5 } & 1 & 2 & 3 & 4 \\
\hline Working conditions (Worker) & 2.75 & 2.75 & 2.75 & 2.75 \\
Health and safety (Worker) & 2.5 & 2.25 & 2 & 2 \\
Access to material resources (Local community) & 1 & 1 & 3 & 3 \\
Delocalization and migration (Local community) & 1 & 1 & 3 & 3 \\
Safe and healthy living conditions & 3 & 3 & 2.75 & 2.75 \\
$\quad$ Local community) & & & & \\
Local employment (Local community) & 1 & 2 & 3 & 3 \\
Secure living conditions (Local community) & 2 & 2 & 1 & 1 \\
Public commitments to sustainability & 1 & 2.5 & 2.5 & 2.5 \\
$\quad$ issues (Society) & & & & \\
Total & 14.25 & 16.5 & 20 & 20 \\
\hline
\end{tabular}

importance is assigned to the environment; its pair-wise comparison and weight results are shown in Table A.6SM and its consistency is acceptable with CR 0.011. Table A.7SM displays the information entropy of the criteria and corresponding weight factors according for each scenario. The weight factors obtained by these two methods are combined in Eq. (2) and the final weight results are presented in Table 5 .
Environment, energy and economy are set to associate with cost criteria, while society is set as benefit criterion. Based on the TOPSIS results presented in Table 5, scenario 3 ranks the first and is the most highly recommended one, scenario 4 follows after with a slight gap and scenario 2 and 1 ranks the third and the last.

\subsection{Sensitivity analysis}

\subsubsection{Weight factors in SLCA}

People's concerns over the safe environment around such facilities and conflicts over the land occupation by the waste treatment facilities are two main social aspects, for which a greater weight should be considered. Results obtained by changing the weight factors of secure living conditions and access to material resource are presented in Figs. 6 and 7. Scenarios 1 and 2 have better performance in terms of secure living conditions and the gap of total social scores between scenarios becomes smaller as its weigh factor increases (see Fig. 6a). When its weight factor exceeds 4.5 , scenario 2 has the best social performance. Regarding access to material resource, scenarios 3 and 4 seem to be the best choices for the society and the gap between these scenarios increases as the weight factor becomes larger. Changing weight factors of social impacts has a small effect on the final $3 \mathrm{E}+\mathrm{S}$ results (see Figs. $6 \mathrm{~b}$ and $7 \mathrm{~b}$ ).

SLCA is still in an early stage of development and there is a lack of standardized characterization method to calculate the social issues (Jørgensen et al., 2008). An appropriate and accepted method for quantifying social issues is highly desired. If a better SLCA method with characterization and weighting for waste treatment technology is created in the future, the $3 \mathrm{E}+\mathrm{S}$ model can be modified without any difficulties.

\subsubsection{Weight factors in $M C D M$}

It is apparent that weight factors in MCDM affect the final result

Table 5

Integrated weight factors and $3 \mathrm{E}+\mathrm{S}$ results by TOPSIS.

\begin{tabular}{|c|c|c|c|c|c|}
\hline Criterion & Weight factor & Scenario 1 & Scenario 2 & Scenario 3 & Scenario 4 \\
\hline Environment & 0.333 & $7.85 \mathrm{E}-12$ & $-7.14 \mathrm{E}-13$ & $-5.13 \mathrm{E}-12$ & $-3.38 \mathrm{E}-12$ \\
\hline Energy & 0.266 & 357.03 & -1367.96 & -2496.61 & -3064.85 \\
\hline Economy & 0.236 & 45.87 & 16.57 & 57.14 & 70.62 \\
\hline Society & 0.165 & 14.25 & 16.5 & 20 & 20 \\
\hline TOPSIS result & & 0.104 & 0.643 & 0.825 & 0.760 \\
\hline
\end{tabular}



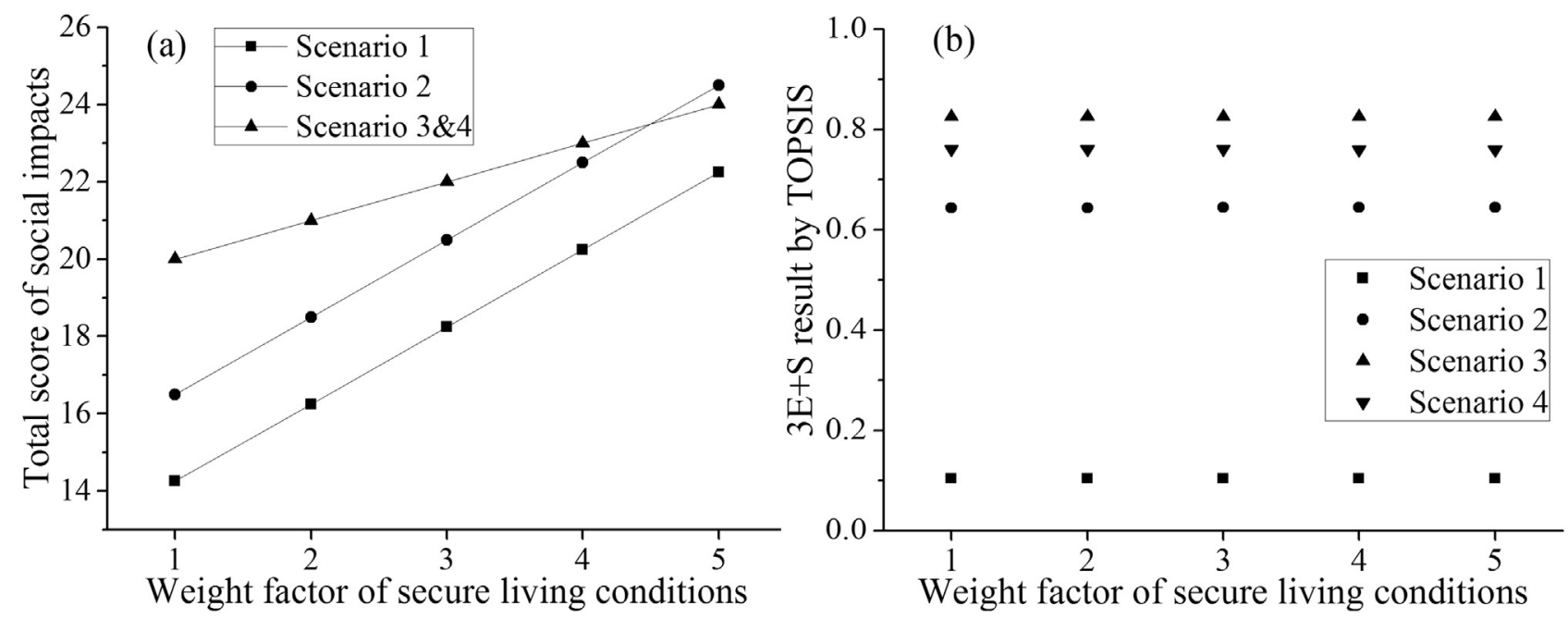

Fig. 6. The effect of changing weight factors of secure living conditions on (a) social results, and (b) $3 E+S$ results.

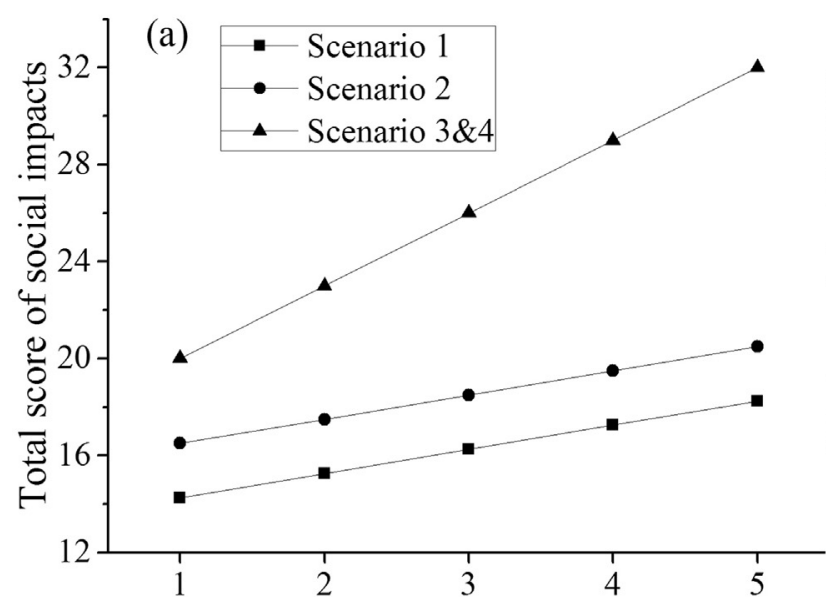

Weight factor of access to material resources

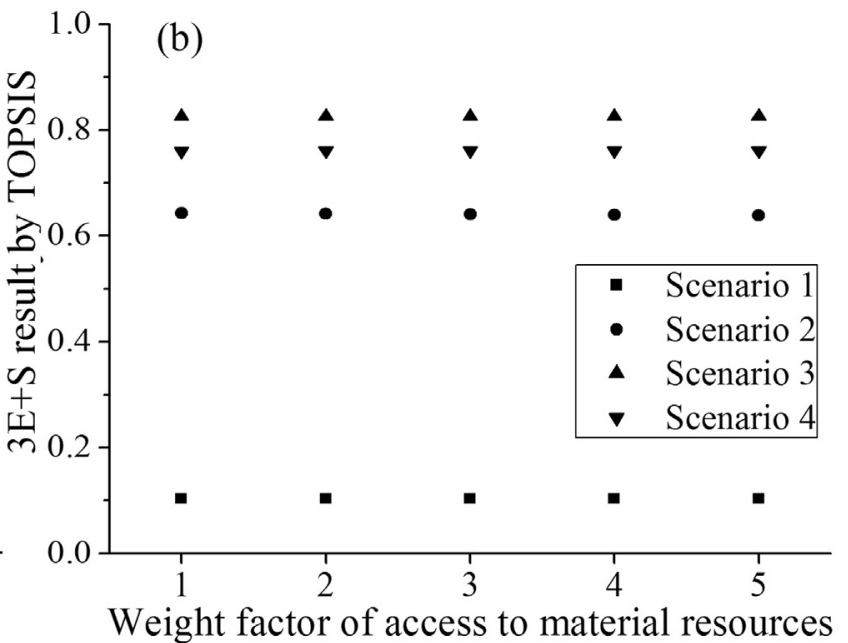

Weight factor of access to material resources

Fig. 7. The effect of changing weight factors of access to material resource on (a) social results, and (b) $3 E+S$ results.

of $3 \mathrm{E}+\mathrm{S}$ model. Weight factors can be changed by a variable $x$ according to Eq. (3):

$u_{j}=x \times w_{j}+(1-x) \times h_{j} ;(0 \leq x \leq 1)$

where, $x$ is the weight variable. When $x$ is set to 1 , the final weight factors are the subjective results obtained by AHP; and when $x=0$, the final weight factors are the objective results obtained by entropy weight method. The detailed weight variations are illustrated in Table A.8SM.

The $3 \mathrm{E}+\mathrm{S}$ results with the variation of weight factors as function of $x$ are shown in Fig. 8. Scenario 3 ranks the first and scenario 4 follows after with a slight gap at the $x$ greater than or equal to 0.1 . When $x=0$, the weight of economy increases to 0.308 and scenario 2 becomes better than scenario 4 . Scenario 1 always ranks the last due to its poor individual $3 \mathrm{E}+\mathrm{S}$ results.

Diverse priorities of each criterion in AHP by different stakeholder groups are also discussed. In addition to government, two other stakeholder groups, enterprise and residents, are considered. For enterprise, economy is the most important factor, while social impact ranks the first for residents (see Table A.9SM). The final ranking obtained by changing the priorities from different

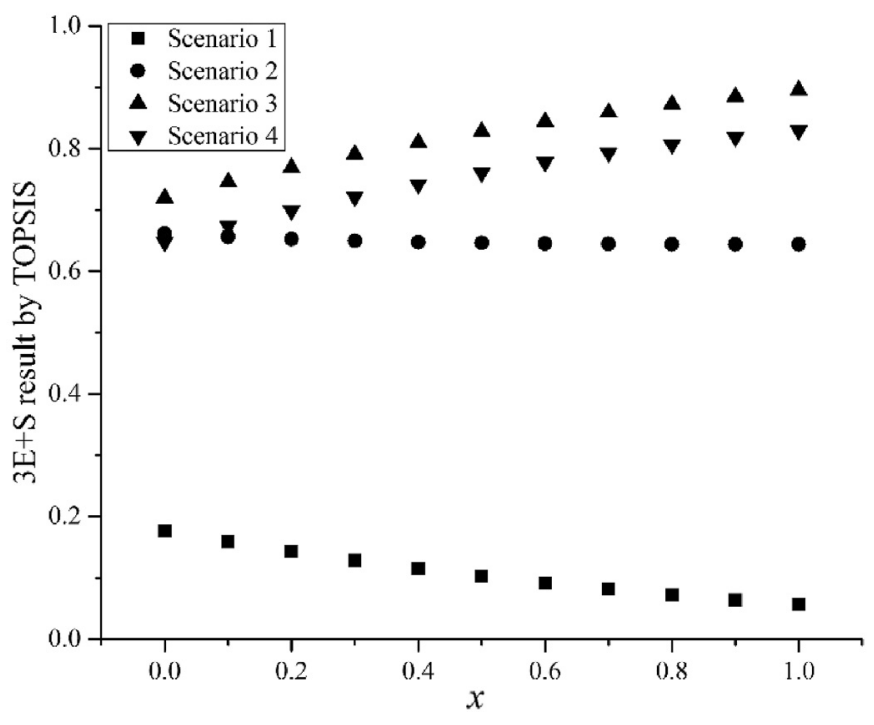

Fig. 8. $3 \mathrm{E}+\mathrm{S}$ results with the variation of weight factors. 


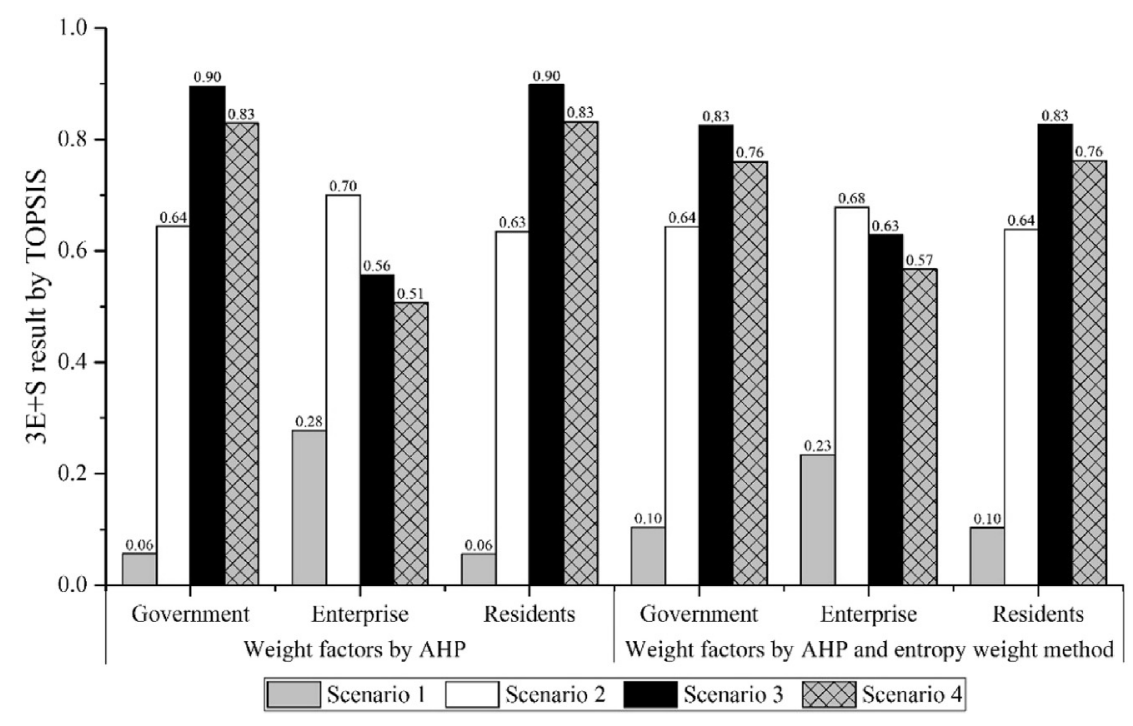

Fig. 9. $3 \mathrm{E}+\mathrm{S}$ results by the weight factors from perspective of different stakeholder groups.

stakeholder groups is presented in Fig. 9. From the perspective of government and resident, the ranking order is not transformed and scenario 3 is the best choice. For enterprise group, the weight of economy is comparatively high and the final result of scenario 2 exceeds those for scenarios 3 and 4 .

The weight factors in this novel $3 \mathrm{E}+\mathrm{S}$ model are calculated by the integration of AHP and entropy weight method, while those in the previous 3E model are only treated by AHP. Fig. 9 compares the $3 \mathrm{E}+\mathrm{S}$ results by the two calculation methods, to verify the effectiveness of the modification for calculating the weight factors. Ranking orders from perspective of different stakeholder groups are consistent by the two calculation methods. In scenarios calculated using AHP and entropy weight method, the gap between $3 \mathrm{E}+\mathrm{S}$ results of the same scenario from perspective of different stakeholder groups is smaller in comparison with that calculated only by AHP. This is because both the requirements of the individual groups and the information of data are considered in the new weight method. The $3 \mathrm{E}+\mathrm{S}$ model has high credibility.

Weight factor analysis is a key part for the $3 \mathrm{E}+\mathrm{S}$ model calculation, and results by the diverse weight factors provide important starting points during actual decision making. In this study, scenario 3 is the best choice for most cases based on the sensitivity analysis, demonstrating strong robustness of the results.

\section{Conclusion}

This study introduces a novel $3 \mathrm{E}+\mathrm{S}$ model for sustainability assessment, in which four criteria (environment, energy, economy, and society) are evaluated from a life cycle perspective and the individual $3 \mathrm{E}+\mathrm{S}$ results are aggregated into one final result by MCDM. In this study, four typical MSW treatment alternatives are evaluated by this model: scenarios 1 and 2 are landfill plants without and with energy recovery; scenarios 3 and 4 are FB and MG incineration plants.

From the perspective of environmental impacts, scenarios 3 and 4 have the two best performances due to the electricity and byproduct production. Scenario 2 has the lowest value of net LCC cost, while scenario 4 ranks the best in energy. Social indicators are benefit criterion and scenarios 3 and 4 have the highest social scores. Aggregated the individual $3 \mathrm{E}+\mathrm{S}$ results, scenario 3 scores 0.825 and is the best choice for sustainable MSW management system; scenario 4 follows after with final score 0.760 , while scenarios 2 and 1 rank the third and the last (score: 0.643 and 0.104).

A new framework of SLCA on MSW treatment technology is built in this study and its further discussion is provided in terms of sensitivity analysis. Greater weight is set to secure living conditions and access to material resource, leading to the change of social results but only a small effect on the final $3 E+S$ results. Weight assignment to each criterion is essential for $3 \mathrm{E}+\mathrm{S}$ model calculation. This new calculation method combines AHP and entropy weight method. Compared to the method in previous work, this method reduces man-made disturbances and has strong robustness. The sensitivity analysis based on weight factors in MCDM demonstrates the effectiveness of the modification for the model. Based on the $3 \mathrm{E}+\mathrm{S}$ model, a scientific and sustainable solution is proposed for decision-maker.

\section{Acknowledgements}

This project is supported by the National Natural Science Foundation of China (No. 51676170) and the Program of Introducing Talents of Discipline to University (B08026).

\section{Appendix A. Supplementary data}

Supplementary data to this article can be found online at https://doi.org/10.1016/j.jclepro.2018.11.074.

\section{References}

Astrup, T.F., Tonini, D., Turconi, R., Boldrin, A., 2015. Life cycle assessment of thermal waste-to-energy technologies: review and recommendations. Waste Manag. 37, 104-115.

Chen, S.J., Hwang, C.L., 1992. Fuzzy Multiple Attribute Decision Making Methods, Fuzzy Multiple Attribute Decision Making. Springer, Berlin, Heidelberg, pp. 289-486.

Chinese Statistics Yearbook Compiling Committee, 2017. Chinese Statistics Yearbook 2016. Chinese Statistics Yearbook Compiling Committee. Chinese Statistics Press, Beijing.

Dong, J., Chi, Y., Zou, D., Fu, C., Huang, Q., Ni, M., 2014a. Comparison of municipal solid waste treatment technologies from a life cycle perspective in China. Waste Manag. Res. 32, 13-23.

Dong, J., Chi, Y., Zou, D., Fu, C., Huang, Q., Ni, M., 2014b. Energy-environment-economy assessment of waste management systems from a life cycle perspective: model development and case study. Appl. Energy 114, $400-408$.

Evangelisti, S., Tagliaferri, C., Clift, R., Lettieri, P., Taylor, R., Chapman, C., 2015. Life 
cycle assessment of conventional and two-stage advanced energy-from-waste technologies for municipal solid waste treatment. J. Clean. Prod. 100, 212-223.

Foolmaun, R.K. Ramjeeawon, T, 2013. Comparative life cycle assessment and social life cycle assessment of used polyethylene terephthalate (PET) bottles in Mauritius. Int. J. Life Cycle Assess. 18, 155-171.

Galli, F., Pirola, C., Previtali, D., Manenti, F., Bianchi, C.L., 2018. Eco design LCA of an innovative lab scale plant for the production of oxygen-enriched air. Comparison between economic and environmental assessment. J. Clean. Prod. 171, 147-152.

Gluch, P., Baumann, H., 2004. The life cycle costing (LCC) approach: a conceptual discussion of its usefulness for environmental decision-making. Buiild. Environ. 39, 571-580.

Govindan, K., Kaliyan, M., Kannan, D., Haq, A.N., 2014. Barriers analysis for green supply chain management implementation in Indian industries using analytic hierarchy process. Int. J. Prod. Econ. 147, 555-568.

Hangzhou Statistics Yearbook Compiling Committee, 2017. Hangzhou Statistics Yearbook 2016. Hangzhou Statistics Yearbook Compiling Committee. Hangzhou Statistics Press, Hangzhou.

Havukainen, J., Zhan, M., Dong, J., Liikanen, M., Deviatkin, I., Li, X., Horttanainen, M. 2017. Environmental impact assessment of municipal solid waste management incorporating mechanical treatment of waste and incineration in Hangzhou, China. J. Clean. Prod. 141, 453-461.

Huang, B., Yang, H., Mauerhofer, V., Guo, R., 2012. Sustainability assessment of low carbon technologies-case study of the building sector in China. J. Clean. Prod. 32, 244-250.

ISO, 2006, second ed.. ISO 14040: Environmental Managementelife Cycle Assessmenteprinciples and Framework Geneva.

Jørgensen, A., Le Bocq, A., Nazarkina, L., 2008. Methodologies for social life cycle assessment. Int. J. Life Cycle Assess. 13, 96-103.

Kloepffer, W., 2008. Life cycle sustainability assessment of products. Int. J. Life Cycle Assess. 13, 89-95.

Li, X., Wang, K., Liu, L., Xin, J., Yang, H., Gao, C., 2011. Application of the entropy weight and TOPSIS method in safety evaluation of coal mines. Procedia Eng 26 2085-2091.

Liu, P., Zhang, X., 2011. Research on the supplier selection of a supply chain based on entropy weight and improved ELECTRE-III method. Int. J. Prod. Res. 49 (3) 637-646.

Martínez-Blanco, J., Lehmann, A., Muñoz, P., Antón, A., Traverso, M., Rieradevall, J., Finkbeiner, M., 2014. Application challenges for the social Life Cycle Assessmen of fertilizers within life cycle sustainability assessment. J. Clean. Prod. 69,
34-48.

Mora, E.S., 1996. Life Cycle Assessment of Municipal Solid Waste Management Alternatives: an Integrated Optimization Model. Master's thesis. North Carolina State University, Raleigh.

Opricovic, S., Tzeng, G.-H., 2004. Compromise solution by MCDM methods: a comparative analysis of VIKOR and TOPSIS. Eur. J. Oper. Res. 156, 445-455.

Othman, S.N., Noor, ZZ. Abba, A.H., Yusuf, R.O., Hassan, M.A.A., 2013. Review on life cycle assessment of integrated solid waste management in some Asian countries. J. Clean. Prod. 41, 251-262.

Risse, M., Weber-Blaschke, G., Richter, K., 2017. Resource efficiency of multifunctional wood cascade chains using LCA and exergy analysis, exemplified by a case study for Germany. Resour. Conserv. Recycl. 126, 141-152.

Saaty, T.L., 1990. How to make a decision: the analytic hierarchy process. Eur. J. Oper: Res. 48, 9-26.

Santoyo-Castelazo, E., Azapagic, A., 2014. Sustainability assessment of energy systems: integrating environmental, economic and social aspects. J. Clean. Prod. 80, 119-138.

Tao, J., Li, L., Yu, S., 2018. An innovative eco-design approach based on integration of LCA, CAD $\backslash$ CAE and optimization tools, and its implementation perspectives. J. Clean. Prod. 187, 839-851.

Thinkstep, 2018. Gabi 8.0 Software-system and Database for Life Cycle Engineering. Copyright, TM, Stuttgart, Entringen.

Umair, S., Björklund, A., Petersen, E.E., 2015. Social impact assessment of informal recycling of electronic ICT waste in Pakistan using UNEP SETAC guidelines. Resour. Conserv. Recycl. 95, 46-57.

UNEP-SETAC, 2009. Guidelines for Social Life Cycle Assessment of Products, first ed UNEP/SETAC life cycle initiative, Belgium.

Vinyes, E., Oliver-Solà, J., Ugaya, C., Rieradevall, J., Gasol, C.M., 2013. Application of LCSA to used cooking oil waste management. Int. J. Life Cycle Assess. 18, 445-455.

Yagmur, L., 2016. Multi-criteria evaluation and priority analysis for localization equipment in a thermal power plant using the AHP (analytic hierarchy process). Energy 94, 476-482.

Yazdani, M., Chatterjee, P., Zavadskas, E.K., Zolfani, S.H., 2017. Integrated QFDMCDM framework for green supplier selection. J. Clean. Prod. 142, 3728-3740.

Zhou, Z., Tang, Y., Chi, Y., Ni, M., Buekens, A., 2018. Waste-to-energy: a review of life cycle assessment and its extension methods. Waste Manag. Res. 36, 3-16.

Zou, Z.H., Yi, Y., Sun, J.N., 2006. Entropy method for determination of weight of evaluating indicators in fuzzy synthetic evaluation for water quality assessment. J. Environ. Sci. 18, 1020-1023. 